UCRL-ID-132390

\title{
Initial Recommendations for Restricting Gamma-Ray Spectrometry Measurements of Radionuclides for On-Site Inspections
}

Steven A. Kreek

William F. Buckley

John F. Wild

November 6, 1998

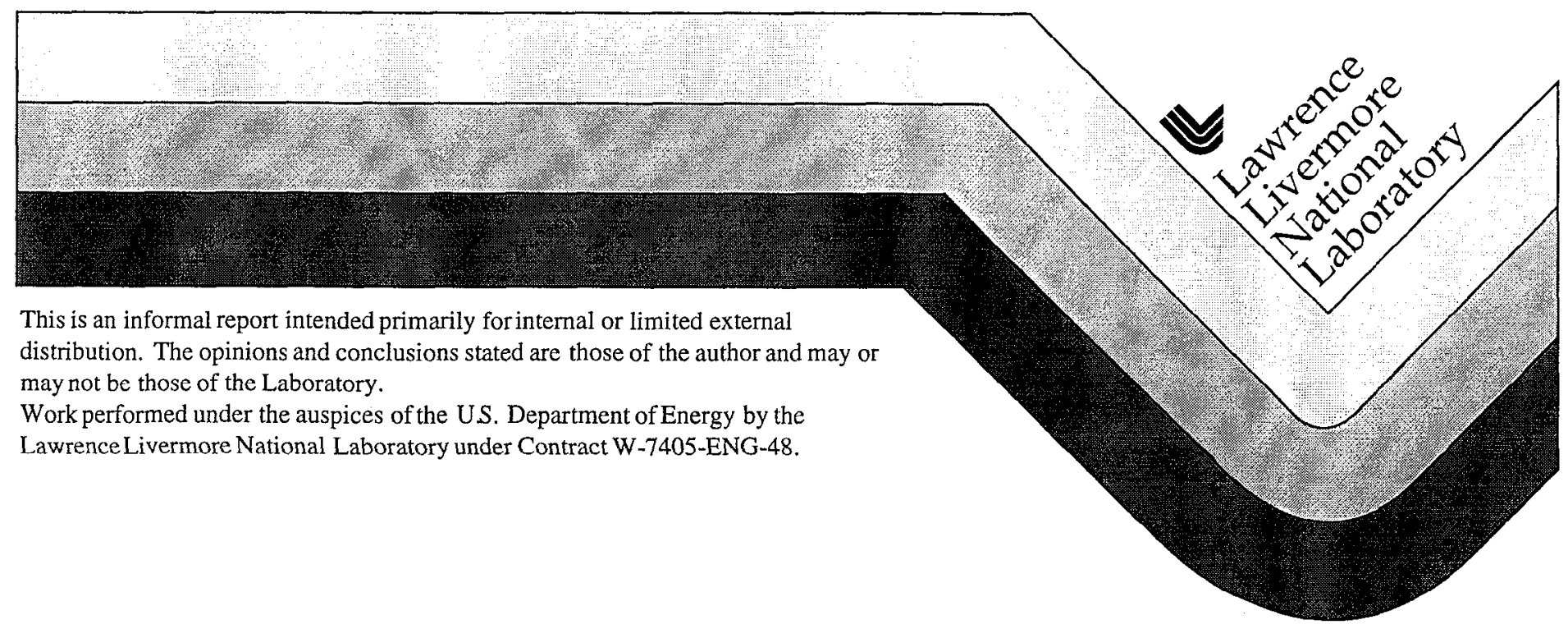




\section{DISCLAIMER}

This document was prepared as an account of work sponsored by an agency of the United States Government. Neither the United States Government nor the University of California nor any of their employees, makes any warranty, express or implied, or assumes any legal liability or responsibility for the accuracy, completeness, or usefulness of any information, apparatus, product, or process disclosed, or represents that its use would not infringe privately owned rights. Reference herein to any specific commercial product, process, or service by trade name, trademark, manufacturer, or otherwise, does not necessarily constitute or imply its endorsement, recommendation, or favoring by the United States Government or the University of California. The views and opinions of authors expressed herein do not necessarily state or reflect those of the United States Government or the University of California, and shall not be used for advertising or product endorsement purposes.

This report has been reproduced directly from the best available copy.

Available to DOE and DOE contractors from the Office of Scientific and Technical Information

P.O. Box 62, Oak Ridge, TN 37831

Prices available from (615) 576-8401, FTS 626-8401

Available to the public from the

National Technical Information Service

U.S. Department of Commerce

5285 Port Royal Rd.,

Springfield, VA 22161 


\title{
Initial Recommendations for Restricting Gamma-Ray Spectrometry Measurements of Radionuclides for On-Site Inspections
}

\author{
Authors: \\ Steven A. Kreek, William F. Buckley, and John F. Wild
}

\begin{abstract}
:
The US paper "Radionuclide Sampling, Sample Handling and Analytical Laboratory Equipment for Comprehensive Test Ban Treaty On-Site Inspections," CTBT/PC/V/OSI/WSII/PR/29 identified the radionuclides of interest to an OSI as ${ }^{144} \mathrm{Ce},{ }^{147} \mathrm{Nd},{ }^{141} \mathrm{Ce},{ }^{140} \mathrm{Ba}\left({ }^{140} \mathrm{La}\right),{ }^{95} \mathrm{Zr}\left({ }^{95} \mathrm{Nb}\right),{ }^{131 \mathrm{~m}} \mathrm{Xe},{ }^{133 \mathrm{~m}} \mathrm{Xe},{ }^{133 \mathrm{~g}} \mathrm{Xe}$, ${ }^{135 g} \mathrm{Xe}$, and ${ }^{37} \mathrm{Ar}$. All of these nuclides (except ${ }^{37} \mathrm{Ar}$ ) can be measured via some form of conventional or coincidence-based gamma-ray spectrometry. The non-gaseous radionuclides $\left[{ }^{144} \mathrm{Ce},{ }^{147} \mathrm{Nd},{ }^{141} \mathrm{Ce}\right.$, ${ }^{140} \mathrm{Ba}\left({ }^{140} \mathrm{La}\right)$, and $\left.{ }^{95} \mathrm{Zr}\left({ }^{95} \mathrm{Nb}\right)\right]$ can be measured via conventional high-resolution gamma-ray spectrometry using a shielded, high-purity germanium (HPGe) detector. The gaseous radionuclides ${ }^{131 \mathrm{~m}} \mathrm{Xe},{ }^{133 \mathrm{~m}} \mathrm{Xe}$, ${ }^{133 g} \mathrm{Xe}$, and ${ }^{135 g} \mathrm{Xe}$ are best measured (after separation from their homologous elements) via a gamma \& beta/electron coincidence technique such as that described in CTBT/WGB/TL-11/5 which could utilize either a HPGe or low-resolution ( $\mathrm{NaI}(\mathrm{Tl})$ ) gamma-ray spectrometer to detect the gamma-ray/x-ray and a plastic scintillator to detect the beta particle/electron from the decay of the various Xe isotopes.
\end{abstract}

The US paper CTBT/PC/V/OSI/WSII/PR/29 (and other papers) identified a need to limit the information that can be extracted from high-resolution gamma-ray spectra to ensure that only information relevant to an OSI is accessible. The term "blinding" has been used to describe the need to limit the information available to the Inspection Team from the high-resolution gamma-ray measurement. A better term is "measurement restriction"; the need for restricting the information is particularly relevant to conventional high-resolution gamma-ray spectrometry measurements, but not to the gamma \& beta/electron coincidence-type measurements envisioned for $\mathrm{Xe}$ isotopes because the separation process for these radionuclides will likely eliminate any other observables. The purpose of this paper is to define functional requirements for restricting measurements via conventional highresolution gamma-ray spectrometry systems to ensure that only the nuclides of interest to an OSI can be identified and quantified. Options discussed below include 1) acquisition and analysis of the entire high-resolution gamma-ray spectrum combined with a limited reporting mechanism, and 2) restricting of the gamma-ray spectrum prior to acquisition and analysis/reporting based upon only the limited portion of the spectrum. It is well recognized that the results should be as accurate as possible, but the analytical work must be performed in a manner consistent with the purposes of an OSI.

\section{Introduction:}

Gamma-ray spectrometry is a long-standing technique used to identify radionuclides by the characteristic radiation signatures associated with their radioactive decay. The advent of high-purity, germanium-based (HPGe), high-resolution, gamma-ray spectrometry permits the identification of many 
different radionuclides, even when present in complex mixtures. The ability to differentiate many overlapping gamma-ray peaks is possible because of the energy resolution achievable with HPGe detectors. The resolving capability of HPGe detectors is illustrated in Figure 1 which shows characteristic gamma-rays (peaks) over the energy range of $50-250 \mathrm{keV}$ for a sample containing enriched uranium. The narrowness of peaks in the HPGe-based spectrum as compared to that achievable via sodium-iodide [ $\mathrm{NaI}(\mathrm{Tl})]$ or cadmium-zinc-telluride (CZT) detector technology illustrates the reason why so many different gamma-rays can be resolved from one another via HPGe. The availability of a database of gamma-ray energies and intensities for the radionuclides of interest then permits identification of complex mixtures even in cases where some of the gamma-rays are not energyresolvable to the HPGe. The gamma-ray energies and intensities for the nuclides of interest to an OSI are presented in Table 1.

\section{Radioisotope Identification Assurance:}

As mentioned previously and as shown in Table 1, many radionuclides emit more than a single gamma-ray. This could be perceived as an added complexity to the job of identifying radionuclides present in a sample. However, the ability to rely on more than one associated gamma ray makes the identification much stronger, particularly for cases in which nuclides emit gamma-rays of similar or the same energy as other nuclides.

One of the most common examples of the case where nuclides emit gamma-rays of similar energy is ${ }^{231} \mathrm{Th}$ (which is naturally occurring, an industrial radioisotope, and the decay product of ${ }^{235} \mathrm{U}$, also a naturally occurring radioisotope), and ${ }^{226} \mathrm{Ra}$ (naturally occurring and a medical / industrial radioisotope). These radionuclides each have their strongest gamma-ray emission at approximately 186 $\mathrm{keV}$ (approximately $186.1 \mathrm{keV}$ for ${ }^{226} \mathrm{Ra}$ and approximately $185.7 \mathrm{keV}$ for $\left.{ }^{231} \mathrm{Th}\left({ }^{235} \mathrm{U}\right)^{\circ}\right)$. These gammarays are only barely resolvable, even with HPGe detectors, and could easily be confused for onc another in the absence of any other information.

Rather than attempt to make the identification of the source of the $186-\mathrm{keV}$ gamma-ray based solely on the $186-\mathrm{keV}$ line, the identification process should be able to rely upon other gamma-rays which appear in the spectrum as well. For the case of ${ }^{231} \mathrm{Th}\left({ }^{235} \mathrm{U}\right)$, other gamma-rays are emitted with intensities similar to that of the 186-keV line. These other emissions occur at $163.3 \mathrm{keV}$ and $143.8 \mathrm{keV}$. If these gamma-rays are also present in the sample and the measured intensities (after correction for detection efficiency, absorption, background, and any additional radionuclides besides ${ }^{231} \mathrm{Th}\left({ }^{235} \mathrm{U}\right)$ and ${ }^{226} \mathrm{Ra}$ which might be present and emit interfering gamma-rays) are similar to the known values, then a ${ }^{231} \mathrm{Th}\left({ }^{235} \mathrm{U}\right)$ identification is likely correct. If the $163.3 \mathrm{keV}$ and $143.8 \mathrm{keV}$ gamma-rays are not present, then a ${ }^{226} \mathrm{Ra}$ identification is likely correct, however the ${ }^{226} \mathrm{Ra}$ identification would be based only upon the single $186.1 \mathrm{keV}$ gamma-ray and is still rather tenuous. If the other gamma-rays (143.8 keV and $163.3 \mathrm{keV}$ ) are present, but with significantly less intensity (after all necessary corrections) than expected as compared to the $186-\mathrm{keV}$ line, then possibly both ${ }^{226} \mathrm{Ra}$ and ${ }^{231} \mathrm{Th}\left({ }^{235} \mathrm{U}\right)$ are present in the sample.

For the nuclides of interest to an OSI, the same sort of ambiguity in identification discussed between ${ }^{231} \mathrm{Th}\left({ }^{235} \mathrm{U}\right)$ and ${ }^{226} \mathrm{Ra}$ could easily arise if the identification is limited to a single gamma-ray. The possible ambiguity could have significant impact to an OSI. As an example using nuclides relevant

\footnotetext{
- The indication of ${ }^{231} \mathrm{Th}$ is shown as ${ }^{231} \mathrm{Th}\left({ }^{235} \mathrm{U}\right)$ because ${ }^{231} \mathrm{Th}$ has a short half-life (1.06 days) and is almost always found in or near equilibrium with the parent ${ }^{235} \mathrm{U}$.
} 
to an OSI, ${ }^{133} \mathrm{Xe},{ }^{144} \mathrm{Ce}$ (OSI nuclides) and other industrial sources such as ${ }^{131} \mathrm{I},{ }^{133} \mathrm{Ba}$ and ${ }^{231} \mathrm{Th}$ (not OSI nuclides) could easily be confused if only the observation of an approximately $80-\mathrm{keV}$ gamma ray was used to make the assignment. The relevant information for this example is shown in Table 2. The list of possible interferences for all of the gamma-rays of interest in Table 1 is very long and is not included here. It is hopefully clear that the more gamma-rays associated with the identification of a particular radionuclide, the more confident the identification of that nuclide.

In addition to requiring the correct set of gamma-rays for a particular radionuclide is the requirement that the ratio of the various gamma-rays be correct. This can be understood from the ${ }^{226} \mathrm{Ra}$ and ${ }^{231} \mathrm{Th}\left({ }^{235} \mathrm{U}\right)$ example mentioned earlier. A detailed examination of the ratio of the measured gammaray intensities, after correction for geometry and adsorption, can indicate whether an interfering activity is present even if the gamma-rays are not energy-resolvable with the HPGe. An example of the gammaray intensity information that could be available to the analyst performing the measurement is shown in Table 3. With a set of information similar in content to that shown in Table 3, the analyst and the OSI team can be assured that the identification is correct.

To further illustrate the possible complexities, an example gamma-ray spectrum of some mixed fission products produced via the thermal neutron irradiation of ${ }^{235} \mathrm{U}$ is shown in Figure 4 . For those nuclides in which identification via conventional gamma-ray detection is appropriate (the non-gaseous nuclides), the use of as many relevant gamma rays as possible should be an integral part of the analysis process. The gamma-ray spectrum shown in Figure 4 is for a sample approximately 2 weeks after irradiation and most of the very short-lived fission products have decayed. However, most of the nongaseous radionuclides relevant to an OSI, ${ }^{95} \mathrm{Zr},{ }^{95} \mathrm{Nb},{ }^{140} \mathrm{Ba},{ }^{140} \mathrm{La},{ }^{141} \mathrm{Ce},{ }^{144} \mathrm{Ce}$, and ${ }^{147} \mathrm{Nd}$ are still present. Since many of the components in a sample such as this have interfering gamma-ray emissions, it is critical that the identification process involve as many of the relevant gamma-ray lines as possible.

\section{Need for Quantification:}

In the most basic sense, quantification of the relevant radionuclides and the determination of the ratios of some of the radioactive species are critical to the determination of whether a nuclear explosion has occurred. Other sources of many of the relevant radionuclides are spread throughout the world. These include industrial and medical sources, as well as typical nuclear reactor and fucl reproccssing operations and could interfere with OSI measurements. Since reactors produce and release virtually all of the radionuclides of interest to an OSI, except ${ }^{37} \mathrm{Ar}$, the ability to determine ratios of radionuclides is critical to identifying whether the source was produced in an instantaneous explosion (a bomb) or via a long, fairly constant, production mechanism such as a typical nuclear reactor. An example of how activity ratios change as a function of time for an instantaneous production of Xe isotopes is illustrated in Figure 2. At a given time, the activity ratios of the nuclides can be examined to see whether they are consistent with a nuclear explosion at the OSI event time or not.

Other uses for isotope ratios include the ability to estimate when the radioactivities were released for subsequent correlation with other OSI information. If the source term is known or can be estimated (the relative amount of the various radionuclides produced), then the relative amount of ${ }^{95} \mathrm{Zr}$ to ${ }^{95} \mathrm{Nb}$ can be used to date the materials shortly after production. The other nuclides such as ${ }^{144} \mathrm{Ce}$ and ${ }^{141} \mathrm{Ce}$ as well as ${ }^{140} \mathrm{Ba}\left({ }^{140} \mathrm{La}\right)$ can also be used for this purpose, but cover slightly different time windows of applicability. Also, the ratio of ${ }^{133 \mathrm{~m}} \mathrm{Xe}$ to ${ }^{133 \mathrm{~g}} \mathrm{Xe}$ and the presence of ${ }^{135} \mathrm{Xe}$ and ${ }^{131 \mathrm{~m}} \mathrm{Xe}$ can be used to determine whether the production was via thermal neutrons (a typical reactor) or a fast-neutron pulsed source (a bomb). 


\section{Discussion of Some Options for Implementation:}

Possible options for implementing a high-resolution gamma-ray spectrometer system for an OSI include:

- Option 1: acquisition and analysis of the entire gamma-ray spectrum combined with a limited reporting mechanism, and

- Option 2: restricting the gamma-ray spectrum prior to acquisition and analysis/reporting to limited portions (regions) of the spectrum.

Issues regarding the assurance with which the identification and quantification take place for each of the options above are briefly discussed in the subsequent sections.

\section{Identification Assurance (Option 1):}

Under option 1 indicated above (acquisition and analysis of the entire gamma-ray spectrum), the subsequent nuclide identifications are likely the most robust. This is because all associated gamma-rays for a particular nuclide can be examined to further ensure that the identifications are correct (see Table 3). This system is likely the easiest to implement as the technology to acquire a gamma-ray spectrum over a large energy range already exists and is commercially available. An interface could be generated which does not permit the analyst to view the entire gamma-ray spectrum during or after acquistion, but instead simply displays the analyzed results in a manner similar to that shown in Table 3 for the nuclides relevant to the OSI or for calibration. If a series of calibration sources with a broad range of associated gamma-ray energies (such as ${ }^{152,154} \mathrm{Eu},{ }^{137} \mathrm{Cs}$ and ${ }^{60} \mathrm{Co}$ ) is available and is measured simultaneously with the samples, then the analyst and OSI can be better assured that the acquisition and analysis system is running correctly. A similar system has already been developed by Lawrence Livermore National Laboratory for a different application and is called the Field Radionuclide Identification System (FRIS).

FRIS is a portable electromechanically cooled HPGe detector and analysis system designed for use by US Customs inspection officials for the identification of medical, industrial and enriched nuclear materials sources. The FRIS system combines the capabilities of a high-resolution gamma-ray spectrometer system with a custom interface that ultimately provides information similar to that listed in Table 3 for each nuclide identified. The system and interface are shown in Figure 3. Something similar to the FRIS system might have application to the OSI in that the actual gamma-ray spectrum is neither displayed or saved to disk. Only the results of the analysis are displayed to the analyst or are saved to disk for future recall.

\section{Identification Assurance (Option 2):}

Option 2 (acquisition of only a portion of the gamma-ray spectrum for subsequent analysis) could potentially provide the needed analytical results, but the large number of possible interferences makes implementation of such a system problematic. This system would likely be prone to misidentifications because so many different possible interferences exist that it may not be possible to configure the system to mitigate all of them ahead of time. In addition, great care would be required to establish exactly which regions of the gamma-ray spectrum need to be analyzed. This adds an additional complexity in that the energy regions would likely have to change with varying measurement conditions such as ambient background, nearby operations, etc. For instance, if low-energy gamma-rays are selected as the target gamma-rays for a particular nuclide, it is presumably because the expected 
intensities offer the best chance of detection. However, if the low-energy region of the spectrum is interfered with by the presence of some large Compton contributing source in the vicinity, then the analysis may have to be adjusted to use the higher energy emissions.

Some of the potential interferences could include $x$-ray sources, peaks resulting from energy summing, single and double escape peaks, high radioactivity background increasing the Compton noise in the lower energy region of the spectrum as well as detector dead-time, or introduction of undisclosed shielding. These potential interferences are in addition to possibly interfering gamma-ray emissions from other isotopes/sources. At this time, there isn't an effective mechanism to deal with energy summing and escape peaks for all cases because the magnitude of these effects are highly dependent upon the specifics of the measurement (the source, it's strength, the physical characteristics of the sample, the detector, etc.). Issues that could arise from interferences such as those described are generally dealt with by the analyst at the time of a particular measurement. Some of these potential interferences can be mitigated via measurement of low-level standard sources simultaneously with samples. But this requirement, in addition to potentially varying available energy regions, may introduce unnecessary complications into the system (are the gamma-rays from the standard sources in regions which can be examined if the regions may have to be adjusted for different measurement scenarios?). The availability of the entire gamma-ray spectrum for analysis would significantly mitigate the impact of these interferences.

While option 2 is possible, the technology to limit the spectra to a series of widely varying energy windows, analyze the data, and provide assurance that the windows remain unchanged and verifiable does not currently exist commercially (to the knowledge of the authors). Also, the ability to deal with background continuum in energy regions of limited width (a necessary part of fitting gammaray peaks) has also not been addressed. Such a system that is capable of performing this type of analysis would require development, particularly in the area of establishing the target energy regions, the background fitting, and assuring that the regions remain constant and verifiable during the analysis.

\section{Quantification Assurance (Option 1 and Option 2):}

For both options described above, the need to have a robust gamma-ray analysis software package is paramount. The code must possess capabilities to account for variable sample size, density, and composition so that the measured gamma-ray intensities can be corrected for geometry and selfabsorption prior to association with an isotope(s). Also, given that some samples could be fairly radioactive, the ability to include and correct for external absorbers is a must. These absorbers may be required to reduce the flux of beta radiation impinging upon the gamma-ray detector. The use of a geometry-specific efficiency calibration is too limiting for the purposes intended in that many of the samples likely to be counted could have significantly varying density, shape, and composition from the calibration standard(s). Since many of the gamma rays of interest are lower in energy ( $80 \mathrm{keV}$, etc.) and the sample sizes envisioned are relatively large, the impact of self absorption at the lower energies is significant. Reliance upon a calibration standard that represents the entire variety of materials to be measured is not recommended.

To ensure the reliability of the gamma-ray analysis, it would be better to use a computational model to calculate the geometric component of the detection efficiency based upon easily measurable quantities. These quantities would include the sample mass, distance to the detector, the sample thickness, sample area, etc. The actual calibration would then involve the intrinsic efficiency of the HPGe detector itself which relies upon generally constant quantities such as the crystal size, crystal 
shape, detector housing thickness, the Ge dead layer, etc. This would increase assurances that the reported results are correct.

Another important characteristic of the analysis code is the ability to separate parent radionuclides from their daughter radionuclides in the identification and subsequent determination of activity concentrations. An example of this would include the separation of ${ }^{95} \mathrm{Nb}$ from ${ }^{95} \mathrm{Zr}$ and ${ }^{140} \mathrm{Ba}$ from ${ }^{140} \mathrm{La}$ and this would greatly improve the identification and quantification capability since these radionuclides may not be in equilibrium at the time of measurement. Commercial gamma-ray analysis codes possess many of these capabilities, but not all. However, alternatives that possess the needed capabilities do exist. These alternative include the LLNL-developed gamma-ray analysis code known as GAMANAL. ${ }^{1}$ The FRIS system described previously utilizes a version of the GAMANAL code to perform the nuclide identifications.

\section{Computer and Software Issues:}

In fielding a system that meets transparency and confidence building criteria, there are apparent conflicting system design requirements. These apparent conflicts can be resolved by implementing something called a 'transparent black-box.' This is a system that collects adequate data and performs sufficient analysis to provide the highest practical confidence in reported conclusions. Since this certainly entails collecting more data and performing more analysis than is acceptable to the host country (such as the entire gamma-ray spectrum), the system must be constructed in such a way that all parties agree that only mutually acceptable information can be obtained from the instrument. This limiting of the reporting and data storage capability of the instrument can be accomplished using a combination of:

- System hardware configuration

- Operating system configuration

- Application software

- Physical and technical security means

\section{System Hardware Configuration:}

The system needs to be configured so that data and analysis information cannot be written to any persistent medium. This is most easily accomplished by creating a bootable CD-ROM with the specially configured OS and application software. A system must also be selected or built using a non-Flash ROM BIOS.

\section{Operating System Configuration:}

The OS needs to be configured such that:

- There is no paging or swapping of physical memory pages. (There is no medium to page or swap to and it is highly desirable to lock physical memory pages so that extraneous copies of data or analyses are not made in physical memory.)

- The user is captive to the application. There are no mechanisms to cscape to the operating system or perform any task other than the agreed upon collection and analysis of data.

\footnotetext{
${ }^{1}$ R. Gunnink, J.B. Niday, "Computerized Quantitative Analysis by Gamma-Ray Spectrometry," Volumes 1-4, Lawrence Livermore National Laboratory Report Number UCRL-51061, 1972.
} 


\section{Analysis Application Software:}

The application software must be written in an understandable, transparent style to perform:

- Adequate data collection and analysis for high-confidence in reported nuclide identifications and quantification results.

- Rigorous testing to ensure that only mutually-agreed windows of spectroscopic data will be viewable during the acquisition, and that only mutually agreed analysis diagnostics, results and conclusions will be viewable.

- All data and analysis information are erased from application memory upon completion of the analysis. All that would remain is a verifiable hardcopy record of the reported results. A unique identifier or some other "check sum" feature must be supplied to ensure that the data is authentic. Perhaps a unique code could be recorded with each analysis report that is based upon the contents of the report and the system would then be able to reproducc the analytical report using this code to verify that the reports are valid.

\section{Physical and Technical Security Measures:}

- filtered power and radiofrequency shielding

- physically secured package for system

- internal tamper countermeasures

- bilateral inspection of equipment

- application of bilateral seals or other tamper-indicating devices on the system

\section{Conclusions:}

The functional requirements for high-resolution gamma-ray spectrometry that meets OSI needs without providing information not relevant to the OSI has been briefly discussed. Much has yet to be defined at this point regarding the specific software and hardware capabilities but this and other documents should serve as some guidance. The primary issues of concern in the design of the analytical methods are:

- Ensuring that the analytical results are correct and valid,

- Use of a system which provides sufficient information that a conclusion can be made (including nuclide identifications, activities, assessment of equilibrium between "allowed" parent and daughter activities $\left[{ }^{140} \mathrm{Ba} /{ }^{140} \mathrm{La},{ }^{95} \mathrm{Zr} /{ }^{95} \mathrm{Nb}\right.$, etc. $]$ as well as isotope ratios for the isotopes of interest to the OSI),

- Providing the results via a robust analysis methodology which is capable of handling a wide variety of measurement scenarios (the analysis code and technique needs to be robust),

- Performing the analysis using as error-free and as tamper-protected a system as possible,

- Designing the system to be as "user-friendly" as possible because the inspectors destined to use the equipment may not be experts in gamma-ray spectrometry.

Given the likely political nature of an OSI, there can be no room for doubt in the conclusions drawn from the analytical data. The data must be as incontrovertible as possible and use of the entire gamma-ray spectrum in the analysis with the limited reporting (Option 1) is much more defensible than handling (limiting) the data prior to analysis (Option 2). 


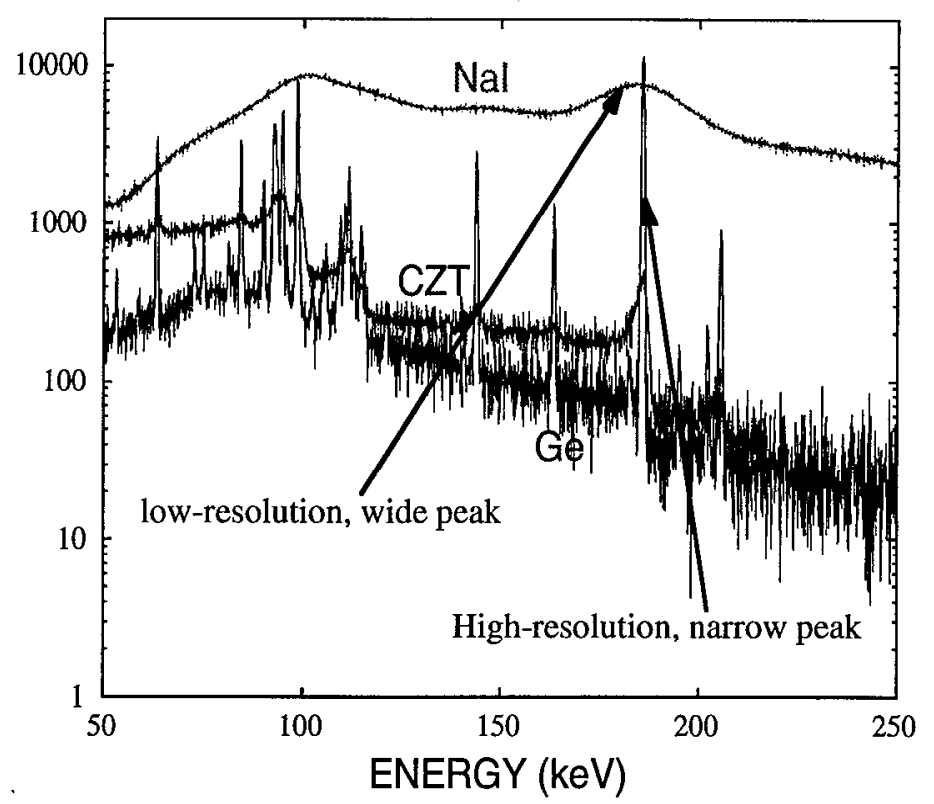

Figure 1. Partial gamma-ray spectrum of a sample containing $U$ as measured by a highresolution, high-purity germanium (Ge in the figure, HPGe throughout the text) detector, a medium-resolution cadmium-zinc-telluride (CZT) detector, and a low-resolution sodium iodide ( $\mathrm{NaI}$ in the figure, $\mathrm{NaI}(\mathrm{Tl})$ in the text) detector. The narrowness of the peaks present in the Ge-based spectrum is the reason why complex mixtures of gammaray emitters can be resolved. This is not true for NaI(Tl)-based systems. CZT-based systems have too little detection efficiency for gamma-rays above about $300 \mathrm{keV}$ to be of great benefit to an OSI at present. 
Table 1. Gamma-ray energies and intensities for the radionuclides of interest to an OSI. The relative intensities detected for given radioisotopes are used to verify that the correct identification has been made (are the relative ratios correct). The halflife is shown in days. ${ }^{2}$

\begin{tabular}{|c|c|c|c|c|c|c|c|c|c|c|c|c|c|c|}
\hline Nuclide & $\begin{array}{c}\begin{array}{c}\text { Half-life } \\
\text { (days) }\end{array}\end{array}$ & $\begin{array}{c}\text { Energy } \\
(\mathrm{keV})\end{array}$ & $\begin{array}{l}\text { Branching } \\
\text { Intensity }\end{array}$ & Error & Nuclide & $\begin{array}{c}\text { Half-life } \\
\text { (days) }\end{array}$ & $\begin{array}{c}\text { Energy } \\
(\mathrm{keV})\end{array}$ & $\begin{array}{l}\text { Branching } \\
\text { Intensity }\end{array}$ & Error & Nuclide & $\begin{array}{c}\text { Half-life } \\
\text { (days) }\end{array}$ & $\begin{array}{c}\text { Energy } \\
(\mathrm{keV})\end{array}$ & $\begin{array}{l}\text { Branching } \\
\text { Intensity }\end{array}$ & Error \\
\hline \multirow[t]{2}{*}{${ }^{95} \mathrm{Zr}$} & $6.50 \mathrm{E}+01$ & 724.2 & $4.42 \mathrm{E}-01$ & 2 & ${ }^{140} \mathrm{Ba}$ & continued & 162.657 & $6.33 \mathrm{E}-02$ & 1 & ${ }^{140} \mathrm{La}$ & continued & 2547.5 & $1.05 \mathrm{E}-03$ & 4 \\
\hline & & 756.72 & $5.46 \mathrm{E}-01$ & 2 & & & 304.852 & $4.22 \mathrm{E}-02$ & & & & 2899.7 & $6.33 \mathrm{E}-04$ & 6 \\
\hline \multirow{3}{*}{$\begin{array}{l}{ }^{93} \mathrm{Nb} \\
{ }^{131 \mathrm{~m}} \mathrm{Xe}\end{array}$} & $3.50 \mathrm{E}+01$ & 765.8 & $9.90 \mathrm{E}-01$ & 2 & & & 423.704 & $3.10 \mathrm{E}-02$ & 1 & & & 3118.3 & $2.51 \mathrm{E}-04$ & 9 \\
\hline & $1.17 \mathrm{E}+01$ & $* *$ & & & & & 437.546 & $1.94 \mathrm{E}-02$ & 1 & ${ }^{141} \mathrm{Ce}$ & $3.24 \mathrm{E}+01$ & 145.44 & 4.93E-01 & 2 \\
\hline & & 163.97 & $1.85 \mathrm{E}-02$ & 5 & & & 537.261 & $2.45 \mathrm{E}-01$ & 1 & ${ }^{144} \mathrm{Ce}$ & $2.85 E+02$ & 80.1 & $1.48 \mathrm{E}-02$ & 3 \\
\hline \multirow[t]{6}{*}{${ }^{133} \mathrm{Xe}$} & $5.23 \mathrm{E}+00$ & 79.6 & $1.48 \mathrm{E}-03$ & 10 & ${ }^{140} \mathrm{La}$ & 1.678 & 109.6 & $2.44 \mathrm{E}-03$ & 6 & & & 133.5 & $1.10 \mathrm{E}-01$ & 2 \\
\hline & & 81 & $3.64 \mathrm{E}-01$ & 5 & & & 131.15 & $4.98 \mathrm{E}-03$ & 4 & & & 696.5 & $1.33 \mathrm{E}-02$ & 4 \\
\hline & & 160.63 & $4.26 \mathrm{E}-04$ & 10 & & & 241.91 & $4.03 \mathrm{E}-03$ & 8 & & & 1163.65 & PAIR PEAK & \\
\hline & & 223.4 & $6.50 \mathrm{E}-06$ & 15 & & & 266.53 & $4.76 \mathrm{E}-03$ & 5 & & & 1489.13 & $2.86 \mathrm{E}-03$ & 5 \\
\hline & & 302.78 & $6.70 \mathrm{E}-05$ & 15 & & & 328.75 & $2.04 \mathrm{E}-01$ & 1 & & & 2185.65 & $7.46 \mathrm{E}-03$ & 5 \\
\hline & & 383.8 & 3.30Е-05 & 15 & & & 432.54 & $2.95 \mathrm{E}-02$ & 1 & ${ }^{147} \mathrm{Nd}$ & 11.04 & 91.1 & $2.78 \mathrm{E}-01$ & 1 \\
\hline \multirow[t]{2}{*}{${ }^{133 \mathrm{~m}} \mathrm{Xe}$} & $2.19 \mathrm{E}+00$ & $* *$ & & & & & 487.03 & $4.57 \mathrm{E}-01$ & 1 & & & 120.49 & $3.50 \mathrm{E}-03$ & 2 \\
\hline & & 233.24 & $1.01 \mathrm{E}-01$ & 10 & & & 574.2 & PAIR PEAK & & & & 196.66 & 1.73E-03 & 2 \\
\hline \multirow[t]{11}{*}{${ }^{135} \mathrm{Xe}$} & $3.79 \mathrm{E}-01$ & 158.3 & $2.40 \mathrm{E}-03$ & 10 & & & 751.66 & 4.37E-02 & 1 & & & 275.42 & $7.65 \mathrm{E}-03$ & 1 \\
\hline & & 249.65 & $9.20 \mathrm{E}-01$ & 5 & & & 815.8 & $2.36 \mathrm{E}-01$ & 1 & & & 319.41 & $1.89 \mathrm{E}-02$ & 1 \\
\hline & & 358.1 & $2.32 \mathrm{E}-03$ & 10 & & & 867.87 & $5.60 \mathrm{E}-02$ & 1 & & & 398.2 & 0.0084 & 1 \\
\hline & & 373.1 & $1.10 \mathrm{E}-04$ & 10 & & & 919.6 & $2.79 \mathrm{E}-02$ & 2 & & & 410.3 & $1.13 \mathrm{E}-03$ & 3 \\
\hline & & 407.78 & $3.29 \mathrm{E}-03$ & 10 & & & 925.25 & $7.04 \mathrm{E}-02$ & 1 & & & 439.8 & 1.17E-02 & 1 \\
\hline & & 573.3 & $5.50 \mathrm{E}-05$ & 10 & & & 951.02 & $5.41 \mathrm{E}-03$ & 5 & & & 489.3 & 0.0014 & 3 \\
\hline & & 607.78 & $2.75 \mathrm{E}-02$ & 5 & & & 1085.2 & PAIR PEAK & & & & 531 & 0.1295 & 1 \\
\hline & & 653.79 & $3.20 \mathrm{E}-04$ & 10 & & & 1499.8 & PAIR PEAK & & & & 589.3 & $3.70 \mathrm{E}-04$ & 6 \\
\hline & & 731.9 & $4.60 \mathrm{E}-04$ & 10 & & & 1596.2 & $9.55 \mathrm{E}-01$ & 1 & & & 594.8 & $2.50 \mathrm{E}-03$ & 2 \\
\hline & & 812.6 & $5.10 \mathrm{E}-04$ & 10 & & & 1837.4 & PAIR PEAK & & & & 680.3 & $1.65 \mathrm{E}-04$ & 10 \\
\hline & & 1063 & $2.80 \mathrm{E}-05$ & 15 & & & 2010.8 & PAIR PEAK & & & & 685.9 & $8.10 \mathrm{E}-03$ & 2 \\
\hline \multirow[t]{2}{*}{${ }^{140} \mathrm{Ba}$} & $1.28 \mathrm{E}+01$ & 118.844 & $7.12 \mathrm{E}-04$ & 7 & & & 2348.4 & $8.12 \mathrm{E}-03$ & 2 & & & & & \\
\hline & & 132.695 & $2.10 \mathrm{E}-03$ & 5 & & & 2521.83 & $3.50 \mathrm{E}-02$ & 1 & & & & & \\
\hline
\end{tabular}

**Xe k-shell x-rays, between approximately 30.3 and $31.0 \mathrm{keV}$.

\footnotetext{
${ }^{2}$ R.J. Nagle and S.A. Kreek, Lawrence Livermore National Laboratory Gamma-Ray Analysis Library, GELIB0892, 1998.
} 


\section{Xe isotope activity as a $f(t)$ for $1 \mathrm{kT}$ of \\ ${ }^{235} \mathrm{U}$ fission; all precursors escape}

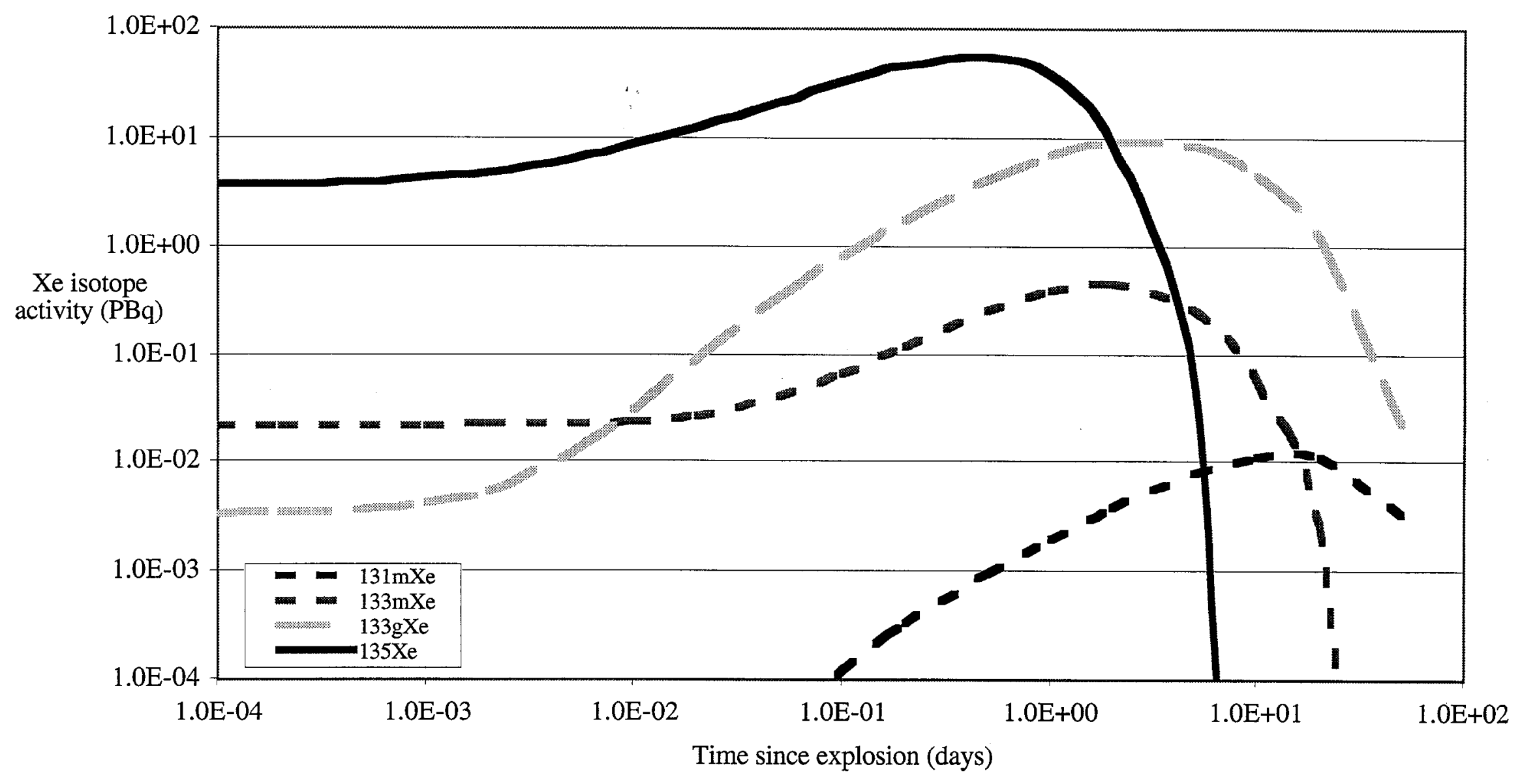

Figure 2. Xe activity as a function of time for a 1 kiloton event in which $100 \%$ of the produced Xe radioactivities and precursor nuclides are released. 
Table 2. Partial list of radionuclides that emit gamma-rays near $80-81 \mathrm{keV} .{ }^{3}$ Without other information such as associated gamma rays, decay information or chemical processing information, it would be very difficult to identify the actual source based solely on the approximately $80-\mathrm{keV}$ line.

\begin{tabular}{|c|c|c|c|}
\hline Isotope & Energy $(\mathrm{keV})$ & Branching Intensity & Associated Gamma Rays \\
\hline${ }^{144} \mathrm{Ce}$ & 80.10 & $1.480 \mathrm{E}-02$ & $133.50,696.50$ \\
\hline${ }^{131} \mathrm{I}$ & 80.16 & $2.280 \mathrm{E}-02$ & $364.46,637.01$ \\
\hline${ }^{133} \mathrm{Ba}$ & 81.00 & $3.352 \mathrm{E}-01$ & $302.75,355.90$ \\
\hline${ }^{133} \mathrm{Xe}$ & 81.00 & $3.640 \mathrm{E}-01$ & 160.63 \\
\hline${ }^{231} \mathrm{Th}$ & 81.23 & $8.900 \mathrm{E}-03$ & $84.21,185.72,163.37,143.77$ \\
\hline
\end{tabular}

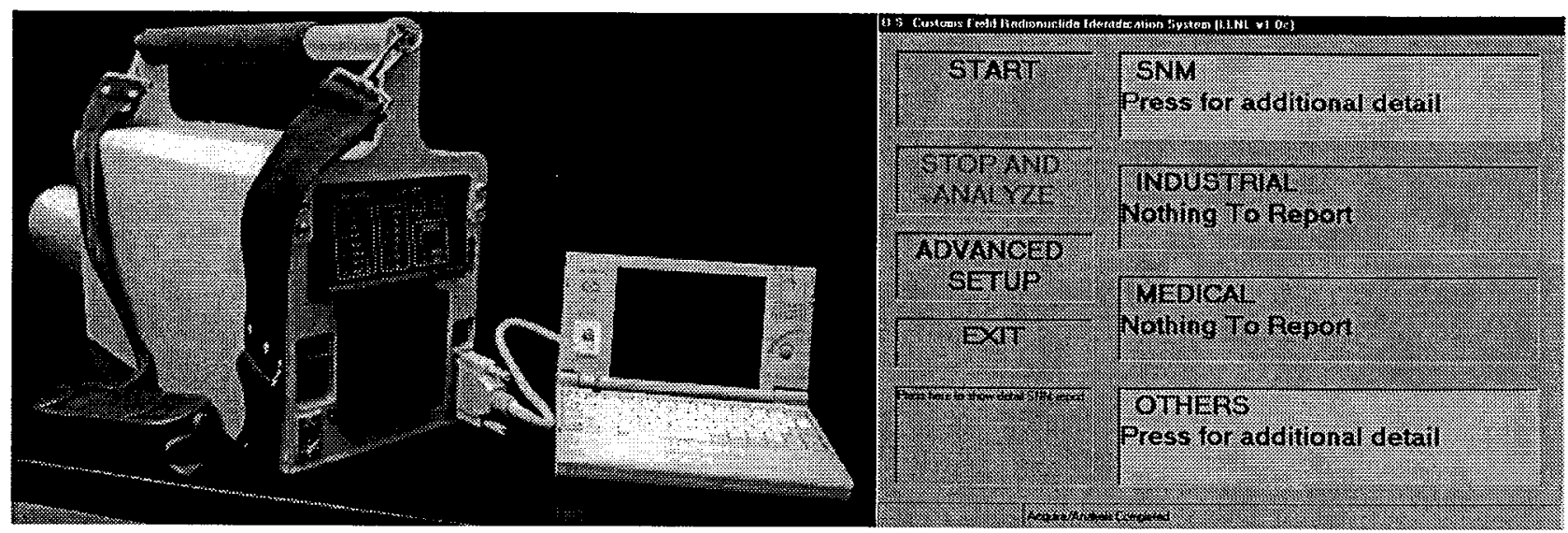

Figure 3. The Field Radioisotope Identification System (FRIS) developed by Lawrence Livermore National Laboratory. The FRIS system identifies three different categories of materials. These include special nuclear materials, industrial radioisotopes and medical radioisotopes. Additional detail is provided in a separate window by clicking on each highlighted category and the additional information is similar to that shown in Table 3.

\footnotetext{
${ }^{3}$ R.J. Nagle and S.A. Kreek, Lawrence Livermore National Laboratory Gamma-Ray Analysis Library, GELIB0892, 1998
} 
Table 3. Hypothetical output listing of associated gamma-rays used in the identification of ${ }^{95} \mathrm{Zr},{ }^{95} \mathrm{Nb}$, and ${ }^{140} \mathrm{Ba}\left({ }^{140} \mathrm{La}\right)$ in a sample. In this case the ${ }^{140} \mathrm{Ba}$ and ${ }^{140} \mathrm{La}$ are in equilibrium and are identified together, the assumption of equilibrium would not be valid for ${ }^{95} \mathrm{Zr}$ and ${ }^{95} \mathrm{Nb}$ in this case (separately

identified). The first three columns (1-3) contain the identification of the nuclides present (1), the calculated activity (2) from all associated gamma-rays (assuming a calibrated system), and the error associated with the calculated activity (3). Column 4 lists all of the gamma-rays observed in the spectrum which are associated with the decay of the nuclide(s) identified in (1). Column 5 shows the activity that would be calculated from the single photon listed in (4). Column 6 shows the fraction of that activity which must be used to reach a statistical minimum with all the other gamma-rays associated (column 4) with the decay of the nuclide(s) indicated in (1). Column 7 shows the statistical error in the gamma-ray peak of interest. Smaller errors are indicative of a more intense peak in the spectrum. Column 8 shows the standard deviation from the group minimum for the peak of interest. Small errors in (7) combined with a number of standard deviation values in column 8 that are small (less than 2-3) indicate a good identification. Column 9 shows possible interferences. Only interfering radionuclides listed as relevant to the OSI are included in this example. Other possible interferences are blacked out to illustrate the magnitude of the potential problem. Similar information to that shown in Columns 1-9 would be available for the other nuclides detected in the sample. The term "trivial" indicates that the nuclide indicated was detected in the sample, but that the contribution to the gamma-ray of interest to this particular nuclide is insignificant and does not effect the identification.

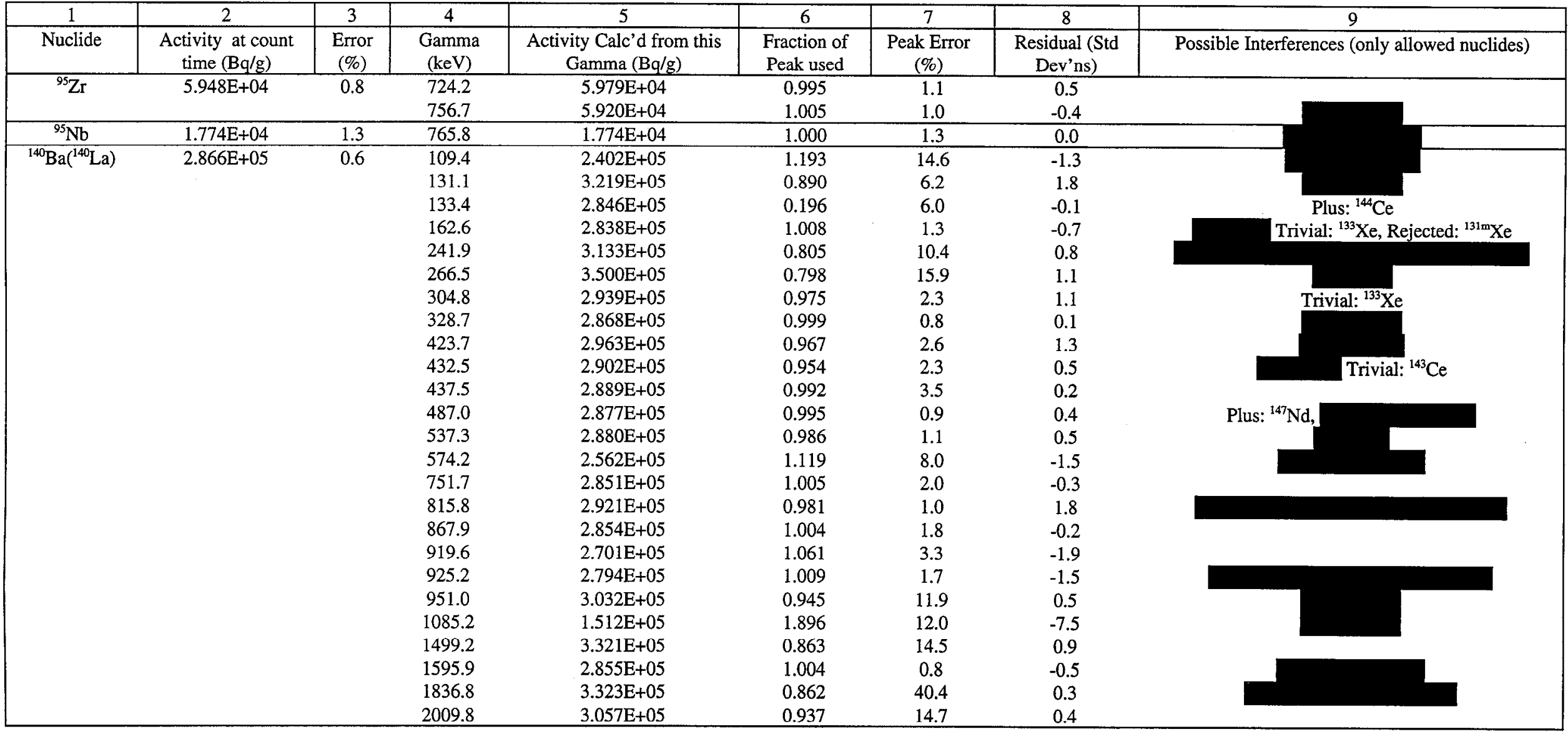




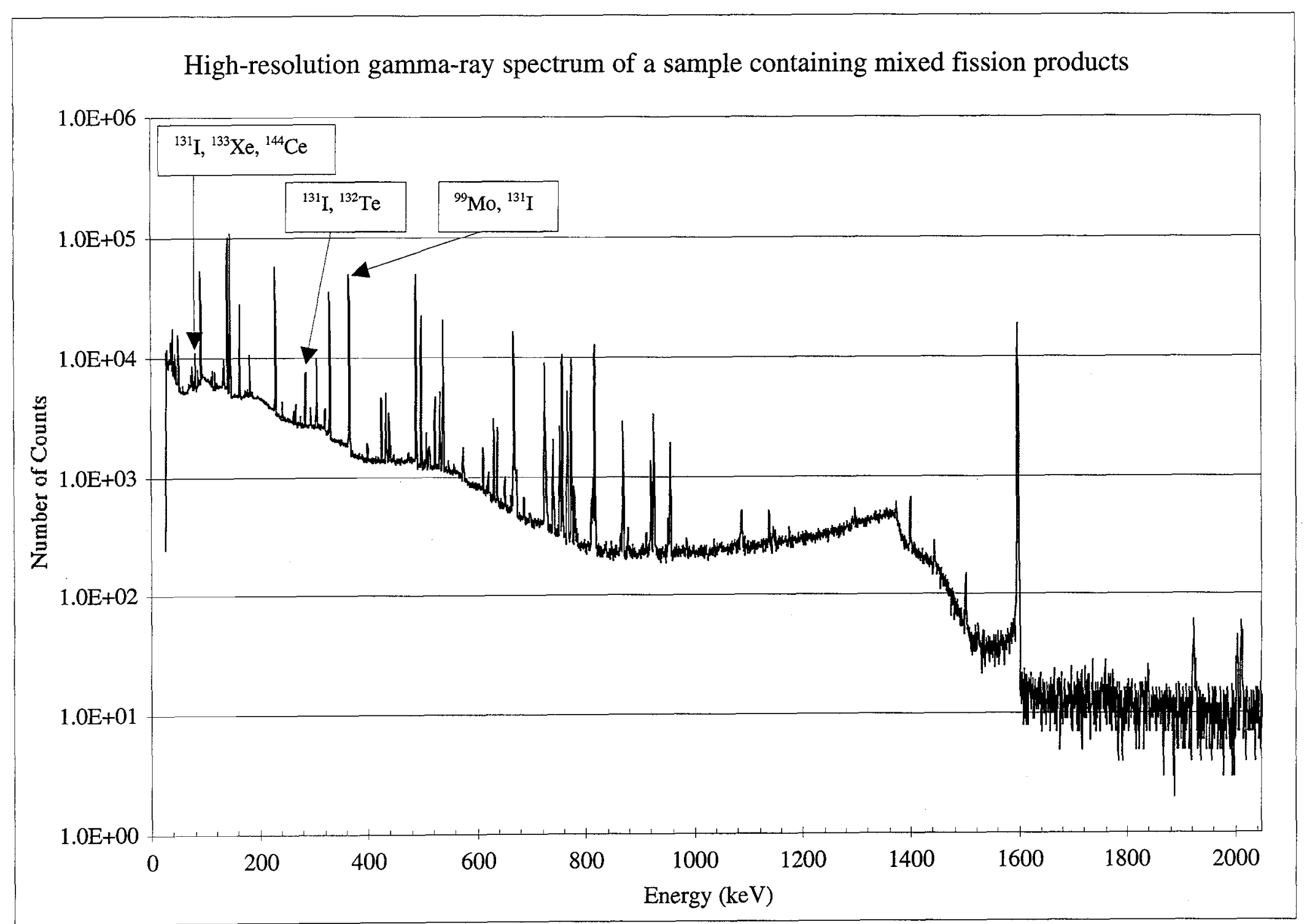

Figure 4. High-resolution gamma-ray spectrum of a solution of mixed fission products containing nuclides of interest to a CTBT OSI. This sample has aged approximately 2 weeks since production. A large number of radionuclides in this sample emit gamma-rays of similar energy requiring the use of more than one gamma-ray to make the identification. 